\title{
Incorrect Patient Position
}

National Cancer Institute

\section{Source}

National Cancer Institute. Incorrect Patient Position. NCI Thesaurus. Code C87033.

An artifact resulting from the incorrect positioning of the patient. 